УДК 330.88

DOI $10.18101 / 2304-4446-2020-2-3-8$

\title{
ЭКОНОМИЧЕСКАЯ СУЩНОСТЬ И ЭТАПЫ ЭВОЛЮЦИИ ЛОВУШКИ ЛИКВИДНОСТИ
}

\author{
() Амагаев Родион Александрович \\ аспирант, Московский государственный университет им. М. В. Ломоносова \\ Россия, 119991, г. Москва, Ленинские горы, д. 1 \\ E-mail: rodion-amagaev@mail.ru
}

Одним из главных вызовов последних лет как для исследователей в области экономической теории, так и для практиков экономической политики стали глобальный финансово-экономический кризис и его не менее масштабные последствия. Глобальный кризис вновь актуализировал интерес к проблеме ловушки ликвидности, поставив в повестку научных обсуждений такие вопросы, как экономическая сущность ловушки ликвидности, с которой столкнулись многие развитые страны мира, и причины их возникновения. В результате глобального финансово-экономического кризиса пострадали практически все страны, особенно остро данная проблема коснулась стран EME (развивающиеся страны). В данной работе отмечается недостаточный интерес со стороны отечественных экономистов к исследованию ловушек ликвидности. Статья посвящена исследованию основных этапов развития взглядов на концепцию ловушки ликвидности.

Ключевые слова: ловушка ликвидности; нетрадиционная монетарная политика; политика нулевых процентных ставок; метод классификации; экономическая сущность; глобальный финансовый кризис.

\section{Для цитирования}

Амагаев Р. А. Экономическая сущность и этапы эволюции ловушки ликвидности // Вестник Бурятского государственного университета. Экономика и менеджмент. 2020. № 2. С. 3-8.

Опыт глобального кризиса подтолкнул экономистов к переосмыслению подходов и методов государственного экономического регулирования, в частности в сфере монетарной политики. Необходимость пересмотра традиционных практик денежно-кредитного регулирования подтвердилась новыми реалиями кризисной и посткризисной мировой экономики. В условиях накопившихся глобальных дисбалансов, дефляционного кризиса развитых стран и стремящихся к нулевому значению номинальных ставок процента меры традиционной монетарной политики становятся практически неэффективными.

Центральные банки развитых стран прибегнули к реализации нетрадиционной монетарной политики для противодействия последствиям глобального кризиса и выхода из ловушки ликвидности. В настоящее время активно обсуждаются вопросы о целесообразности и результативности осуществленных мер, в частности мер по количественному смягчению. В рамках научных дискуссий уделяется внимание вопросам разработки альтернативных мер нетрадиционной монетарной политики, функционирования денежно-кредитной трансмиссии в условиях четвертой промышленной революции и внедрения ИТ в практику активного монетарного регулирования. 
Рассматривая вопрос разработанности проблемы, следует отметить, что в отечественной экономической науке данной проблеме уделено недостаточное внимание и явление ловушки ликвидности в работах исследователей упоминается в основном косвенно. Среди отечественных исследователей, чьи работы напрямую связаны с проработкой вопросов экономической сущности ловушки ликвидности и эффективности монетарной политики в условиях ловушки ликвидности, можно выделить М. Абрамову, Н. Сапункову, группу авторов, представленную О. Кузнецовой, С. Мерзляковым, С. Пекарским. Сложившийся уровень разработанности темы исследования со стороны отечественной экономической науки может быть объяснен тем, что экономические параметры отечественной экономики далеки от параметров развитых стран, попавших в ловушку ликвидности.

В зарубежной литературе тема исследования раскрыта в большей мере и число научных работ, посвященных как теоретической стороне ловушки ликвидности, так и практическим аспектам реализации нетрадиционной монетарной политики, отражает объективную потребность в исследованиях, обозначенную социальноэкономическими предпосылками глобального финансово-экономического кризиса.

Зарубежные исследования, касающиеся тех или иных аспектов ловушки ликвидности, представлены работами таких видных экономистов, как А. Мелцер (A. Meltzer), Д. Фишер (D. Fisher), Р. Эйснер (Robert Eisner), П. Кругман (P. Krugman), Б. Бернанке (B. Bernanke) и многих других.

Однако, несмотря на многообразие исследований, можно отметить отсутствие единого системного взгляда на вопросы об экономической сущности и классификации ловушек ликвидности и подходах к экономико-математическому моделированию. Данные вопросы представляются в качестве перспективных областей для дальнейших исследований. Несомненно, тема исследования актуальна и для отечественной экономики, поскольку, несмотря на многочисленные санкции в отношении России, в условиях финансовой глобализации и развития концепции мировой ловушки ликвидности рассматриваемое явление может стать реальностью и для России.

Проведенный анализ научных работ и публикаций зарубежных исследователей, посвященных исследованию проблем реализации монетарной политики в условиях ловушки ликвидности, околонулевых (ZIRP, zero interest rate policy) или даже отрицательных номинальных ставок процента, позволил определить экономическую сущность ловушки ликвидности, выделить несколько основных этапов развития концепции ловушки ликвидности и событий, которые предлагаются в качестве основных причин, побудивших научный интерес к данной проблеме.

В целом в результате исследования было выделено шесть основных этапов развития концепции ловушки ликвидности (табл. 1).

Все этапы развития концепции ловушки ликвидности характеризуются наличием общего понимания об экономической сущности ловушки ликвидности предполагается, что ловушка ликвидности - это макроэкономическая ситуация, в условиях которой денежно-кредитная политика становится неэффективной. Такие факторы, как реальные экономико-социальные события, уровень развития прикладных экономических наук, тенденция к финансово-экономической глобализации, оказали существенное воздействие на предположения и выводы о практической возможности, причинах и последствиях рассматриваемой ситуации. 
Таблица 1

Эволюция концепции ловушки ликвидности

\begin{tabular}{|c|c|c|}
\hline Период & Авторы & Характеристика периода развития \\
\hline $\begin{array}{c}\text { 30-е гг. } \\
\text { XX в. }\end{array}$ & $\begin{array}{c}\text { Дж. Кейнс, } \\
\text { Дж. Роберт- } \\
\text { сон }\end{array}$ & $\begin{array}{l}\text { Идея ловушки ликвидности появилась в рамках кейнсиан- } \\
\text { ского направления под влиянием Великой депрессии и } \\
\text { была впервые описана в «Общей теории занятости, про- } \\
\text { цента и денег» Дж. Кейнса [2, с. 78]. Важно отметить, что } \\
\text { сам Дж. Кейнс не именовал описываемую им ситуацию в } \\
\text { качестве ловушки ликвидности и впервые данная ситуация } \\
\text { была обозначена как ловушка ликвидности, или «liquidity } \\
\text { trap», в работах Дж. Робертсона [10], однако в контексте, } \\
\text { несколько отличающемся от современных представлений } \\
\text { о данной проблеме }\end{array}$ \\
\hline \multirow[t]{2}{*}{$\begin{array}{c}\text { 40-60-е гг. } \\
\text { XX в. }\end{array}$} & $\begin{array}{c}\text { Дж. Хикс, Ф. } \\
\text { Модильяни, } \\
\text { Э. Хансен и } \\
\text { др. }\end{array}$ & $\begin{array}{l}\text { Определены фундаментальные различия между классиче- } \\
\text { ской экономикой и стандартной интерпретацией кейнси- } \\
\text { анской экономики. Базовое различие сведено к возможно- } \\
\text { сти достижения равновесия в условиях неполной занято- } \\
\text { сти, а концепция ловушки ликвидности является теорети- } \\
\text { ческим конструктом, позволяющим объяснить возмож- } \\
\text { ность такого равновесия. } \\
\text { Дж. Хикс [3, с. 10] определяет ловушку ликвидности как } \\
\text { специальный вариант кейнсианский теории, Ф. Модильяни } \\
\text { [8, р. 13] определяет ловушку ликвидност в качестве } \\
\text { «особого кейнсианского случая». На данном этапе разви- } \\
\text { тия концепция приобретает более формализованные чер- } \\
\text { ты и становится теоретической моделью, имеющей прин- } \\
\text { ципиальную роль в кейнсианской теории }\end{array}$ \\
\hline & $\begin{array}{c}\text { А. Лейон- } \\
\text { хуфвуд }\end{array}$ & $\begin{array}{l}\text { Наследие Кейнса подверглось множественным интерпре- } \\
\text { тациям как со стороны последователей, так и со стороны } \\
\text { критиков. К числу видных исследователей можно отнести } \\
\text { А. Лейонхуфвуда }[9, \text { р. 20], отвергавшего интерпретации } \\
\text { Дж. Кейнса, основанные на принципиальной роли ловушки } \\
\text { ликвидности в кейнсианской теории }\end{array}$ \\
\hline $\begin{array}{c}\text { 70-80-е гг. } \\
\text { XX в. }\end{array}$ & $\begin{array}{c}\text { М. Фридман, } \\
\text { Дж. Штейн и } \\
\text { др. }\end{array}$ & $\begin{array}{l}\text { Дискуссия монетаристов и кейнсианцев. Критика монета- } \\
\text { ристов основывалась на: 1) эффекте Пигу; 2) интерпрета- } \\
\text { ции М. Фридмана количественной теории. Сам М. Фрид- } \\
\text { ман [7, р. 206] определял ловушку ликвидности как случай } \\
\text { кейнсианской экономики номинальных жесткостей, одна- } \\
\text { ко Д. Патинкин [9, р. 12] критиковал такой подход к про- } \\
\text { блеме, отмечая принципиальную роль ловушки ликвидно- } \\
\text { сти в кейнсианской экономике гибких цен. } \\
\text { Меры, предпринимаемые центральным банком, или так } \\
\text { называемые вертолетные деньги, исключают возможность } \\
\text { существования ловушки ликвидности, как отмечает Дж. } \\
\text { Штейн [11, р. 397-419], если центральный банк может до- } \\
\text { пустить дополнительное и непредвиденное увеличение } \\
\text { денежной массы для распределения среди экономических }\end{array}$ \\
\hline
\end{tabular}




\begin{tabular}{|c|c|c|}
\hline & & $\begin{array}{l}\text { агентов, то впоследствии следует ожидать увеличение по- } \\
\text { требительских расходов из-за изменения соотношения } \\
\text { между предельной полезностью хранения денег и пре- } \\
\text { дельной полезностью владения товарами или услугами, } \\
\text { которое ранее находилось в равновесии }\end{array}$ \\
\hline $\begin{array}{c}\text { 90-е гг. XX } \\
- \\
\text { начало } \\
\text { XXI в. }\end{array}$ & $\begin{array}{c}\text { П. Кругман, } \\
\text { Б. Бернанке, } \\
\text { М. Гертлер, } \\
\text { Дж. Акер- } \\
\text { лоф, Дж. } \\
\text { Бенхабиб, } \\
\text { С. Шмидт- } \\
\text { Гроэ, М. } \\
\text { Урибе и др. }\end{array}$ & $\begin{array}{l}\text { На данном этапе общие характеристики исследуемой про- } \\
\text { блемы остаются прежними. Концепция ловушки ликвидно- } \\
\text { сти рассматривается в контексте таргетирования инфляци- } \\
\text { онных ожиданий, совокупного выпуска, отстающего от } \\
\text { тренда, номинальных ставок, достигших критической от- } \\
\text { метки. } \\
\text { Анализ концепции ловушки ликвидности дополнился } \\
\text { предположениями о значимости демографического факто- } \\
\text { ра (П. Кругман) и институциональных особенностей финан- } \\
\text { совых рынков (экономические трения). «Премии за внеш- } \\
\text { нее финансирование (ехtеrnal finance premium)», введен- } \\
\text { ные Б. Бернанке, М. Гертлером [6, р. 27-48], и «рынок ли- } \\
\text { монов» Дж. Акерлофа [5] позволили предположить, что } \\
\text { ввиду повышенной премии за внешнее финансирование и } \\
\text { существования «рынка лимонов» в финансовом секторе } \\
\text { ловушка ликвидности может возникнуть даже при наличии } \\
\text { у коммерческих банков избыточных резервов. Дж. Бенха- } \\
\text { биб, С. Шмидт-Гроэ, М. Урибе [12, р. 7] дополнили анализ } \\
\text { категориями теории «солнечных пятен» (sunsроt theоry), } \\
\text { предположениями о возможном существовании множе- } \\
\text { ственных равновесий }\end{array}$ \\
\hline
\end{tabular}

Важно отметить, что представители классической и неоклассической денежных теорий не обращались к анализу экономических ситуаций или моделей, которые на текущий момент экономическая наука признает в качестве ловушек ликвидности. Вероятно, что данное обстоятельство может быть объяснено тем, что упомянутые теории априори не допускают возможность существования ловушек ликвидности.

Особое место в развитии концепции занимают представители кейнсианской школы. Буквальное прочтение Дж. Кейнса позволяет судить о том, что экономист предполагал возможность потери монетарными органами эффективного контроля над нормой процента и тем самым допускал возможность существования предельного случая общей теории - ловушки ликвидности, отмечая, что подобная ситуация может приобрести важное практическое значение в будущем [2, с. 78], что, несомненно, подтверждается, если обратиться к многочисленным исследованиям в области нетрадиционной монетарной политики зарубежных стран в период глобального финансово-экономического кризиса и во время посткризисного этапа.

На этапе критики концепции ловушки ликвидности монетаристы отмечали, что монетарная политика в любом случае эффективна, дополнительное и непред- 
виденное предложение денег центральным банком способно привести экономику в новое состояние равновесия с более высокими ценами, однако, как показала действительность (например, опыт Японии [4] и глобальный кризис последних лет), данный рецепт работает не всегда и не везде.

Развитие денежной теории и научные дискуссии между экономистами кейнсианского и монетаристского направлений показали, что аргументация последних имеет ряд ограничений. По мнению М. Блауга [1, с. 654], анализ монетарной политики с учетом эффекта реальных остатков может существовать только в рамках метода сравнительной статики и мало применим для рассмотрения вопроса кейнсианской динамики. Что касается «вертолетных денег», то, как показала действительность, эффект от подобных мер не соответствует вложенным в них ожиданиям. Таким образом, политика ZIRP и явление ловушки ликвидности также представляли большой теоретический интерес и в периоды высокой инфляции и относительно высоких номинальных процентных ставок на протяжении 70-80-х гг. XX в.

Следующая волна экономических исследований приходится на период 90-х гг. XX в. Восстановление интереса к теме исследования в данный период времени может быть объяснено не только возросшей необходимостью в развитии теории, но и реальными обстоятельствами (устойчивая тенденция к падению инфляции, номинальных процентных ставок в США и в ряде европейских стран, опыт «японской ловушки», или японского финансово-экономического кризиса), требовавшими разработки практических рекомендаций по преодолению ловушки ликвидности. Именно опыт «японской ловушки», ставшей одним из крупнейших национальных экономических кризисов века, представляется существенным поводом к возобновлению исследований в области политики ZIRP и концепции ловушки ликвидности.

По мнению автора, глобальный финансово-экономический кризис можно рассматривать в качестве наиболее серьезного импульса, побудившего общественность вновь обратиться к проблемам политики ZIRP и ловушки ликвидности.

Проведенное исследование зарубежной литературы дает возможность сделать однозначный вывод, что в экономической науке преобладает консенсус, в соответствии с которым ловушка ликвидности перестала быть просто гипотетической ситуацией, имеющей все необходимые теоретические обоснования, и является экономической действительностью для многих развитых стран в период глобального финансово-экономического кризиса и на посткризисном этапе.

\section{Литература}

1. Блауг М. Экономическая мысль в ретроспективе: пер. с англ. 4-е изд. М.: Дело Лтд, 1994. $720 \mathrm{c.}$

2. Кейнс Дж. М. Общая теория занятости, процента и денег: пер. с англ. М.: ЭКСМО, 2007. $472 \mathrm{c}$.

3. Хикс Дж. Господин Кейнс и классики: Попытка интерпретации / пер. с англ. Е. И. Николаенко. М.: Директмедиа Паблишинг, 2008. 16 с.

4. Файншмидт Р. И., Канаев Е. А. Многостороннее сотрудничество в АТР на фоне глобальных тенденций // Актуальные проблемы Европы. 2016. № 1. С. 96-117.

5. Akerlof G. A. The Market for Lemons: Quality Uncertainty and the Market Mechanism. Quarterly Journal of Economics. 1970. Vol. 84, No. 3. P. 488-500. 
6. Bernanke B., Gertler M. Inside the Black Box: The Credit Channel of Monetary Policy Transmission // Journal of Economic Perspectives. 1995. Vol. 9, No. 4. P. 27-48.

7. Fridman M. A. Theoretical Framework for Monetary Analysis // J.P.E. 1970. Vol. 78. P. $193-238$

8. Modigliani F. Liquidity Preference and the Theory of Interest and Money. Econometrica. 1944. Vol. 12. P. 45-88.

9. Patinkin D. Friedman on the Quantity Theory and Keynesian Economics. Journal of Political Economy. 1972. Vol. 80, No. 5. P. 883-905.

10. Robertson D. H. Some Notes on Mr. Keynes' General Theory of Interest. Essays in Monetary Theory. 1940. Vol. 51. P. 168-191.

11. Stein J. L. The Optimum Quantity of Money by Milton Friedman // Journal of Money, Credit and Banking. 1970. Vol. 2, No. 4. P. 1-50.

12. Inflation targets and the liquidity trap. Working paper series. No. 272. European Central Bank. 2003. 54 p.

\section{ECONOMIC SUBSTANCE AND EVOLUTIONARY STAGES OF A LIQUIDITY TRAP}

Rodion A. Amagaev

Research Assistant, Lomonosov Moscow State University

1 Leninskiye Gory, Moscow 119991, Russia

E-mail: rodion-amagaev@mail.ru

The global financial and economic crisis and its no less essential consequences have become the top challenges of recent years for both researchers in the field of economic theory and practitioners of economic policy. The global crisis renewed interest in the problem of liquiddity traps, putting on the agenda of scientific discussions such issues as the economic substance of liquidity traps, which many developed countries of the world faced, and the causes of their occurrence. Almost all countries were affected by the global financial and economic crisis, especially it concerns EME countries (developing countries). We have noted the lack of attention to the study of liquidity traps by domestic economists. The article analyzes the main stages in the development of views on the concept of a liquidity trap.

Keywords: liquidity trap; unconventional monetary policy; zero interest rate policy; classification method; economic substance; global financial crisis. 